\title{
Reciclagem de PET Advindo de Garrafas de Refrigerante Pós-Consumo.
}

\author{
Sandro D. Mancini, Maxwell N. Bezerra e Maria Zanin
}

Resumo: A reciclagem de PET pós-consumo foi investigada a partir de cinco ciclos sucessivos de moldagem por injeção. Amostras obtidas em cada passo foram submetidas a ensaios para determinar a cristalinidade, degradação, produtividade, fluidez e propriedades mecânicas. Os resultados indicam que a garrafa é reciclável em termos de processamento, principalmente nos quatro primeiros passos. O número de grupos terminais carboxílicos aumentou cerca de $300 \%$ da primeira até a quinta reciclagem, indicando quebra de cadeias. Esta degradação e o aumento da cristalinidade (de $11 \%$ para a garrafa moída para $25 \%$ na quinta reciclagem) explicaram as alterações nas propriedades mecânicas.

Palavras-chave: PET pós-consumo, reciclagem mecânica, injeção, titulação e propriedades mecânicas.

\section{Introdução}

O plástico conquistou espaço de grande importância para a sociedade atual graças às propriedades como leveza, razoável resistência mecânica e moldabilidade a baixa temperatura, aliadas ao preço baixo. Porém, os rejeitos plásticos, devido a pouca degradabilidade e baixa densidade, ocupam vastos espaços no ambiente por um longo tempo. Com o crescente uso deste tipo de material, principalmente na área de embalagens, cujo descarte é muito mais rápido quando comparado a outros produtos, tem-se um agravamento da situação dos locais de destino de lixo ${ }^{[1,2]}$.

Analisando os aspectos ambientais do gerenciamento de resíduos sólidos urbanos, cada vez mais são importantes estudos que provem que a reciclagem dos plásticos é viável. Atualmente, um dos plásticos de maior presença no lixo urbano é o poli(tereftalato de etileno) (PET). Num estudo feito numa cidade paulista de médio porte (Araraquara-SP, de aproximadamente
200 mil habitantes), foi determinado que o PET diz respeito a $34 \%$ em peso dos plásticos presentes no lixo urbano (a exceção dos filmes) e $42 \%$ em volume, aproximadamente. Foram feitos ainda cálculos que estimaram que nesta cidade se consome mais de $7 \mathrm{mil} / \mathrm{dia}$ garrafas de refrigerante (de 2 litros) feitas do plástico. Isso significa que, para o caso da reciclagem de resíduos sólidos de PET, o problema não é a falta de matéria prima. A contaminação, o baixo preço da resina virgem e a dificuldade de coleta são problemas maiores, assim como a falta de confiança, em termos de propriedades, dos consumidores com relação aos plásticos reciclados ${ }^{[3]}$.

A equação química apresentada na Figura 1, mostra a polimerização do PET a partir da condensação de uma molécula de etileno-glicol (EG) com uma de ácido tereftálico (TPA) (que pode ser substituído por Tereftalato de dimetila-DMT). Para a indústria de garrafas de refrigerante tem sido preferido um copolímero feito a base de EG, TPA e ciclohexanodimetanol $^{[4]}$. 


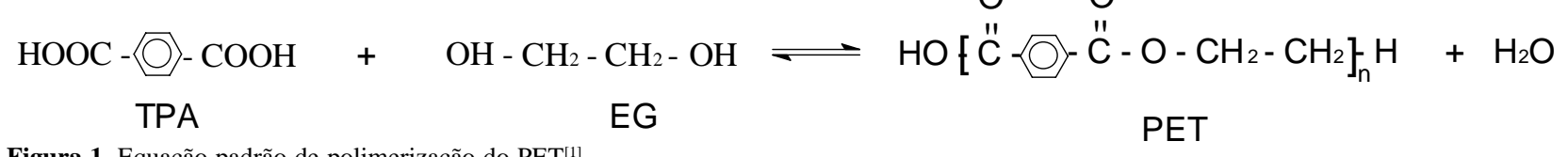

Figura 1. Equação padrão de polimerização do $P E T^{[1]}$

O PET, além das degradações comuns que ocorrem com a maioria dos plásticos (por oxidação, térmica, mecânica e por UV), pode sofrer hidrólise, fazendo com que a equação química da Figura 1, que é reversível, ocorra na direção dos reagentes. Separada ou combinadamente, agentes degradantes como água, oxigênio, calor, raios UV e esforços mecânicos, normalmente encontrados durante o ciclo de vida do PET (processamento, uso, descarte e reciclagem), degradam química e/ou estruturalmente o polímero, alterando principalmente seu peso molecular e consequentemente algumas propriedades ${ }^{[5-10]}$. A reciclabilidade do PET (normalmente por extrusão) tem sido estudada no sentido de se monitorar a diferença de propriedades (mecânicas, principalmente) conforme se processam as reciclagens ${ }^{[11]}$.

Estimativas termodinâmicas dão conta que das ligações químicas intramoleculares do PET a que necessita de menor energia para se romper é a ligação $\mathrm{C}-\mathrm{O}$, mais especificamente a ligação $\mathrm{CH}_{2}-\mathrm{O}(84 \mathrm{kcal} / \mathrm{mol})$, menos que a ligação $\mathrm{O}=\mathrm{C}-\mathrm{O}(88 \mathrm{kcal} / \mathrm{mol})^{[6]}$. Isto leva a concluir que durante o ciclo de vida da garrafa de PET a tendência é que aumentem o número de grupamentos terminais carboxílicos, uma vez que nestas etapas ocorrem degradações comuns (hidrólise, térmica, oxidativa, por UV, etc.) que geram preferencialmente este tipo de grupamento terminal. Um estudo em separado de cada tipo de degradação mostra porém que aumentam outros grupos terminais (como alquila e hidroxila), além da geração de acetaldeído que, mesmo em pequenas quantidades, pode alterar o gosto do alimento acondicionado por uma embalagem feita com o material ${ }^{[1,5-10,12]}$.

É objetivo deste trabalho avaliar a reciclabilidade de garrafas de refrigerante pós-consumo feitas de PET a partir da influência de múltiplas injeções na estrutura (quebra de cadeias e cristalinidade) e seu reflexo em propriedades do PET pós-consumo (produtividade, fluidez, tração e impacto).

\section{Parte Experimental}

Todo o desenvolvimento experimental foi realizado no Laboratório de Polímeros do Departamento de Engenharia de Materiais da Universidade Federal de São Carlos, a exceção das titulações (para a determinação do número de grupos terminais carboxílicos) que foram feitas no Departamento de Fármacos e Medicamentos da Faculdade de Ciências Farmacêuticas da Universidade Estadual Paulista (UNESP), campus de Araraquara.

\section{Obtenção dos corpos de prova e simulação das reciclagens}

Cerca de 5 quilos de garrafas de refrigerante de 2 litros foram coletadas no Depósito de Lixo de Coleta Seletiva da Universidade Federal de São Carlos. A seguir, este material foi moído (em moinho de facas Primotécnica, 738 rpm e 4HP), lavado (com água) e submetido a secagem ao ar por 48 horas e a vácuo de $10^{-1} \mathrm{~atm}$, por 3 horas a $110^{\circ} \mathrm{C}$ (em Mufla EDG, Modelo FIVE 2).

Posteriormente, o material moído em forma de flocos foi injetado (em injetora PIC, tipo BOY-15) em um molde resfriado em água corrente e com cavidades no formato de corpos de prova de tração (tipo I da norma ASTM D 638-90 ${ }^{[13]}$ ). Após a injeção foram novamente moídos, submetidos a secagem à vácuo e injetados. Este procedimento se repetiu até completar cinco injeções, simulando assim as reciclagens. Ao final de cada injeção, uma parte dos corpos de prova foi separada para testes de tração e impacto, e o restante foi moído tomando o cuidado de reservar certa quantidade de flocos para os testes de densidade, índice de fluidez e titulação.

\section{Medição da Produtividade}

A produtividade do PET pós-consumo no processamento por injeção foi medida pelo tempo em que a injetora levou para fundir quantidade suficiente para a injeção de um corpo de prova completo e sem rebarbas (tempo de dosagem).

\section{Medição do Número de Grupos Terminais Carboxílicos}

O número de grupos terminais carboxílicos foi medido usando-se o Método de Poh ${ }^{[14]}$, que consiste numa titulação de PET moído diluído em álcool 
benzílico a quente a partir de solução padrão de hidróxido de sódio em álcool benzílico.

\section{Medição do Índice de Fluidez}

O índice do fluidez do PET foi medido em um equipamento da Custom Scientific Instruments, Modelo 127-G-3-233/110V, segundo a norma ASTM D $1238-90 b^{[15]}$. Adotou-se as seguintes condições: temperatura de $265^{\circ} \mathrm{C}$, pré-aquecimento de 3 minutos e peso de $325 \mathrm{~g}$.

Um alto valor nesta propriedade significa que, quando fundido, o material flui com mais facilidade que uma outra com índice de fluidez menor. Logo, é estabelecida uma relação inversa com relação à viscosidade do polímero.

\section{Medição da Cristalinidade por Densidade}

A densidade do PET foi obtida a partir da imersão de grânulos do polímero em mistura de álcool etílico e tetracloreto de carbono, respectivamente, menos e mais denso que o PET. Quando o grânulo atingiu o nível central do líquido, preencheu-se um picnômetro de 50 $\mathrm{ml}$ com este líquido e pesou-se. A relação massa/volume foi então corrigida com a densidade da água na temperatura do teste (mantida a $23^{\circ} \mathrm{C}$ ). Desta maneira, a cristalinidade é calculada por meio da expressão $1^{[16]}$ :

$$
C=(\rho-\rho a) /(\rho c-\rho a) \times 100
$$

onde:

$\mathrm{C}=$ porcentagem de cristalinidade da amostra;

$\rho=$ densidade da amostra;

$\rho \mathrm{a}=$ densidade da fase amorfa

$\rho c=$ densidade da fase cristalina

Para o PET, $\rho$ a e $\rho c$ são tabelados e equivalem a $1,331 \mathrm{~g} / \mathrm{cm}^{3}$ e $1,455 \mathrm{~g} / \mathrm{cm}^{3}$, respectivamente ${ }^{[17]}$.

\section{Medição da Resistência ao Impacto}

Os corpos de prova de impacto de formato adequado à norma ASTM D 256-90b $\mathrm{b}^{[18]}$ foram entalhados e ensaiados em equipamentos da Custom Scientific Instruments.

\section{Medição das Propriedades de Tração}

Corpos de prova de cada passo de injeção foram submetidos ao teste de tração em Máquina Universal de Ensaios Ínstron, modelo 1172, seguindo a norma ASTM D 638-90 ${ }^{[13]}$. Dos resultados obtidos, serão apresenta- dos o módulo de Young (medida da rigidez do material), o alongamento na ruptura (o quanto o material esticou até quebrar) e a tenacidade (dificuldade de se fraturar o material), obtida a partir da integração da curva força versus deformação obtida no ensaio. A unidade utilizada para quantificar a tenacidade é Joules/metro $(\mathrm{J} / \mathrm{m})$, uma vez que a força é registrada em Newtons $(\mathrm{N})$ e a deformação $\left(\Delta \mathrm{l} / \mathrm{l}_{0}\right)$ em metro/metro $(\mathrm{m} / \mathrm{m})$

\section{Resultados e Discussões}

Nos resultados de produtividade apresentados na Figura 2, pode-se observar que o tempo de processamento quase não se altera para os três primeiros passos de reciclagem. A tendência de aumento do tempo necessário para a dosagem conforme se aumenta o número de reciclagens é nítida e acompanhada de um aumento do desvio-padrão em relação ao número de reciclagens, este último causado pelas dificuldades em injetar os flocos, principalmente no quinto passo de reciclagem.

A título de comparação, determinou-se também o tempo de injeção dos "pellets" do material virgem (fornecidos pela Fibra Nordeste S.A.), que ficou em torno de 12 segundos. Como o tempo de injeção dos flocos da garrafa moída, pela Figura 2, foi de 14,5 segundos, podemos concluir que a reciclagem de PET pós-consumo por injetoras é viável, não sendo exigido, necessariamente, a passagem por um sistema de extrusão/picotamento, normalmente feita para obtenção de grânulos do material, para posterior injeção e que submeteria o material a mais degradações decorrentes deste processamento adicional.

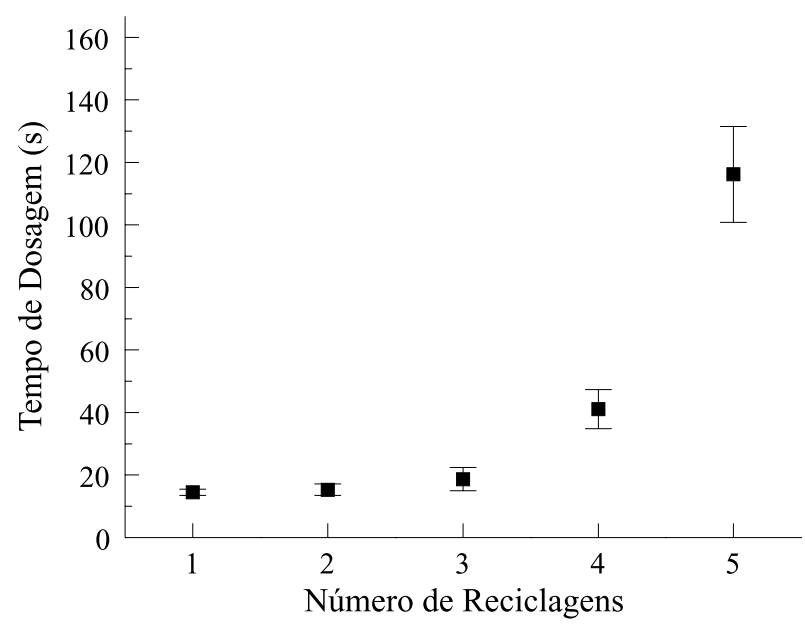

Figura 2. Medidas do tempo de processamento por injeção (dosagem) de amostras provenientes de garrafas em função do número de reciclagens 


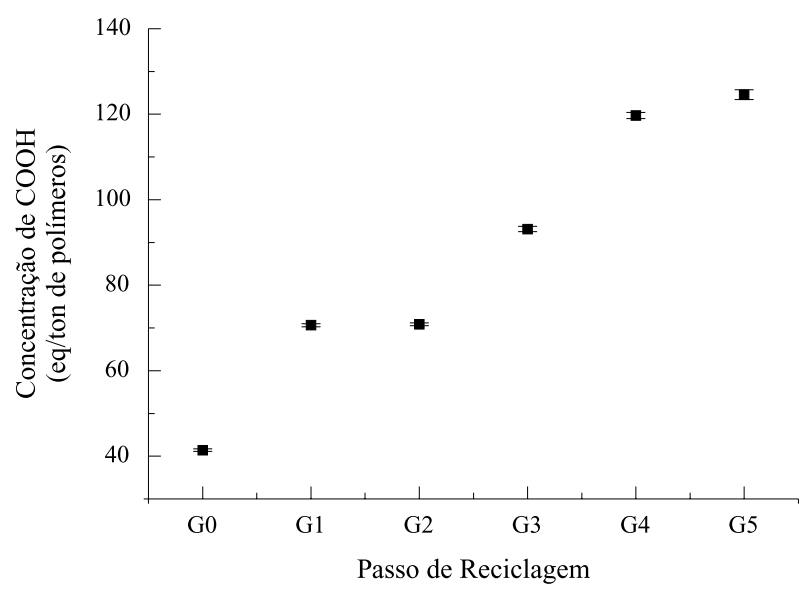

Figura 3. Concentração de grupos terminais carboxílicos para o PET advindo de garrafas em função do número de reciclagens

O aumento no tempo de processamento conforme se recicla o material é decorrente, possivelmente, da diminuição da viscosidade (comprovada no teste de índice de fluidez, Figura 4) e da presença crescente de pó (advindo do processo de moagem) que dificulta a fusão dos flocos.

Os resultados das titulações, apresentados na Figura 3, indicam que há um aumento no número de terminais carboxílicos conforme se aumentam as reciclagens. Este comportamento, que normalmente é esperado, está relacionado a sucessivas passagens por moinho, mufla e injetora, que acarretam esforços mecânicos e/ou temperatura associados com agentes degradantes (como luz, ar e água) que degradam o material gerando grupos terminais carboxílicos, entre outros $^{[5-11]}$. Segundo a Figura 3, o maior aumento se dá do material da garrafa moída (G0) para a garrafa reciclada e moída (G1) da ordem de $70 \%$, sendo que cinco processamentos sucessivos nas condições efetuadas geram aumento de cerca de $300 \%$. Isto indica perda de peso molecular do polímero, resultante da quebra de cadeias. Além de indicarem degradação que já ocorreu no material, a presença de grupos terminais carboxílicos pode ser indício de degradação futura, na medida em que catalisam a hidrólise.

A Figura 4 apresenta as medidas do Índice de Fluidez do Fundido das amostras de PET advindos de garrafas em função do número de reciclagens. Observa-se que o Indice de Fluidez aumenta com o número de reciclagens, indicando viscosidade decrescente. Isto é mais um forte indício de queda no peso molecular (e/ou da piora de sua distribuição), conforme se processam as as reciclagens. Este comportamento da figura pode ser explicado pelo aumento da concentração de grupos terminais

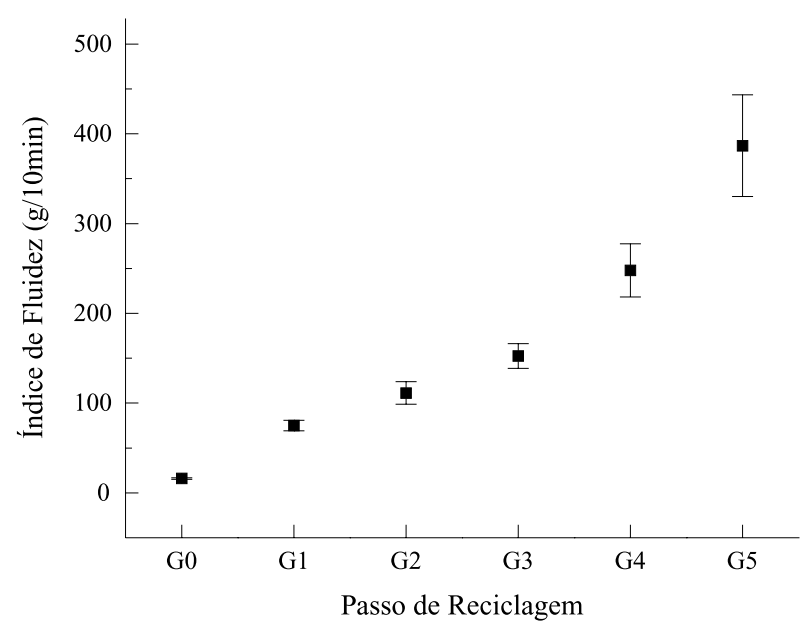

Figura 4. Medidas do Índice de Fluidez em função do número de reciclagens de PET advindo de garrafas

carboxílicos, pois quanto maior o número de terminais - $\mathrm{COOH}$, maior também é o número de cadeias menores, as quais tem facilidade para deslizar entre as cadeias maiores quando no estado fundido, fazendo escoar mais material. Para $\mathrm{G}_{0}$ (garrafa moída), o índice está na faixa de 15,98 g/10 min, saltando para $56,4 \mathrm{~g} / 10 \mathrm{~min}(250 \%)$ para $\mathrm{G}_{1}$. Ao final dos cinco passos, o índice aumentou cerca de 20 vezes em relação a $\mathrm{G}_{0}$.

Outro dado interessante que pode ser constatado na Figura 4 é o aumento do desvio padrão conforme se processam as reciclagens. Este comportamento ilustra a dificuldade de realização da medida para índices relativamente altos.

Os resultados da obtenção da cristalinidade das amostras por densidade (equação 1) são apresentados na Figura 5. Em linhas gerais, o índice de cristalinidade representa o percentual de fase organizada na estrutura do polímero, correspondendo a uma fase mais rígida que a região amorfa (desorganizada). A cristalização fornece ao material mais resistência mecânica, embora diminua sua capacidade de deformação.

Observa-se, pela Figura 5, uma manutenção na média da cristalinidade de G0 para G1. Posteriormente, é clara a tendência de aumento na cristalinidade conforme se processam as reciclagens, resultado da quebra de cadeias e de maior eficiência em se empacotar (quando da fusão), gerando regiões cristalinas. A título de ilustração, determinou-se a cristalinidade do grânulo do material virgem, que ficou próxima a $38 \%$, muito acima do máximo atingido, no quinto passo de reciclagem das garrafas. Tal cristalinidade é comum para o PET empregado na indústria de refrigerantes. Durante a injeção em molde frio da pré- 


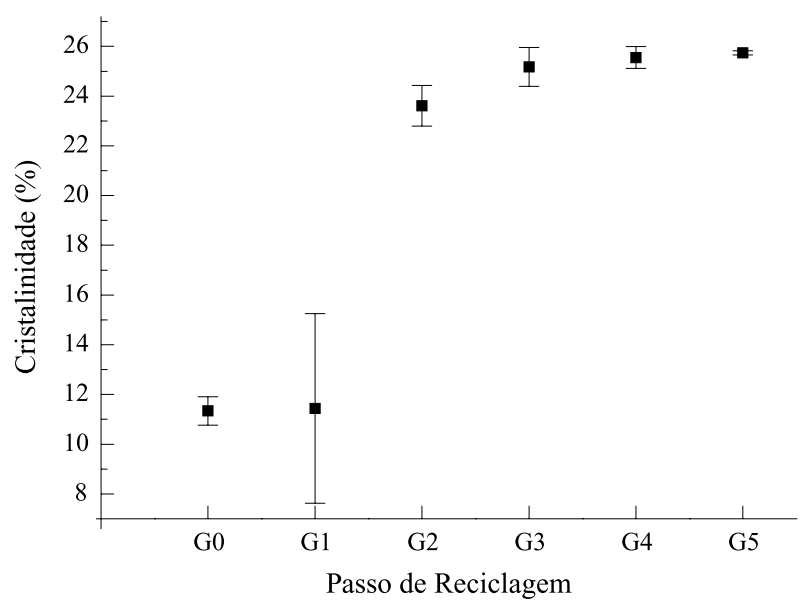

Figura 5. Medidas da cristalinidade (obtida por densidade) para PET advindo de garrafas em função do número de reciclagens

forma esta cristalinidade vai ser parcialmente perdida, fazendo com que, além da transparência necessária, a garrafa possua boas propriedades mecânicas e de barreira a oxigênio e gás carbônico devido a cristalinidade residual (G0). As diferenças nos valores de densidades entre o grânulo do material virgem e a garrafa moída $\left(1,378 \mathrm{~g} / \mathrm{cm}^{3}\right.$ e $1,345 \mathrm{~g} / \mathrm{cm}^{3}$, respectivamente) que forneceram as diferentes cristalinidades explicam porque nas indústrias recicladoras não é comum utilizar o artifício de se misturar PET recuperado (moído) com grânulos do virgem para obter um produto com propriedades intermediárias. A homogeinização fica dificultada, exigindo a passagem por um sistema de extrusão e picotamento, para obter granulados de densidade superior ao moído. Ainda nesta figura, observa-se que o desvio-padrão do primeiro passo de reciclagem $(\mathrm{G} 1)$ é elevado, em virtude da garrafa reciclada ter sofrido efeitos mais pronunciados do resfriamento nas paredes do molde, o que permitiu a ocorrência de regiões (superfície e centro da amostra) com cristalinidades diferentes. Tal diferença foi comprovada visualmente, ao observar flocos de G1 transparentes e opacos, provenientes de uma mesma amostra.

Os resultados dos ensaios de resistência ao impacto podem ser vistos na Figura 6, onde se nota uma acentuada tendência de queda no valor da propriedade com o número de reciclagens. Ainda, observa-se que o desvio-padrão diminui principalmente até o terceiro passo. Do primeiro ao quarto passo nota-se queda de $67 \%$ no valor da resistência ao impacto que pode ser explicada pela diminuição do peso molecular provocado pela quebra de cadeias. Outra explicação é a própria cristalinidade, que pode ter ocorrido a partir do crescimento da estrutura esferulítica, formando um caminho

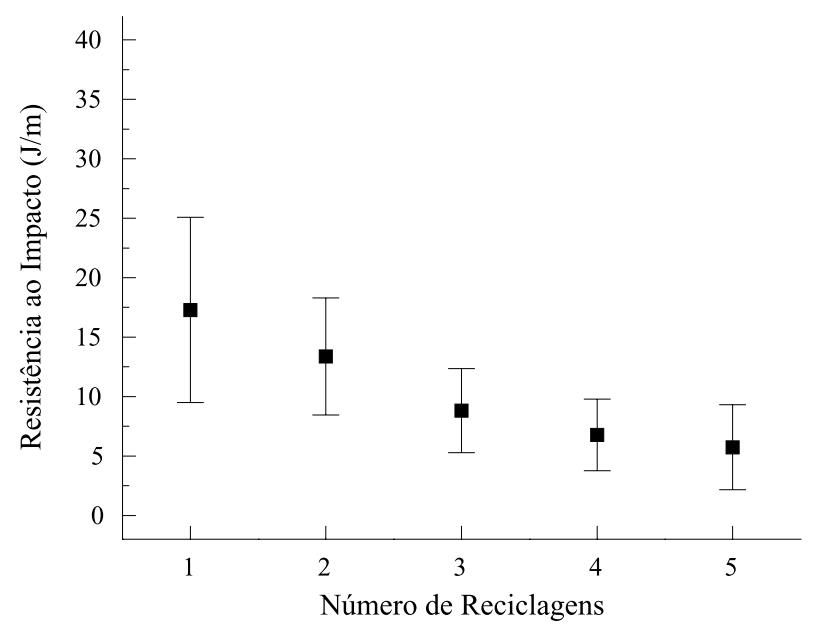

Figura 6. Medidas de resistência ao impacto em amostras provenientes de garrafas em função do número de reciclagens

inter-esferulítico propício para a propagação da trinca representada pelo entalhe. $\mathrm{O}$ aumento da cristalinidade, observado na Figura 5, interfere também na queda da resistência ao impacto, na medida em que diminui a resposta dútil à fratura, típica da fase amorfa.

As Figuras 7, 8 e 9 apresentam alguns resultados dos testes de tração, respectivamente os de módulo de elasticidade (ou de Young), de alongamento na ruptura e de tenacidade. Os resultados do quinto passo de reciclagem devem ser analisados com cuidado, mesmo quando acompanham as tendências, pois especificamente estes corpos de prova apresentaram chupagem (desníveis de relevo na superfície da peça), decorrente do processamento, exatamente onde estas amostras se romperam. A análise das tendências destas propriedades deve ser feita com reservas devido aos seus desvios-padrão. Mesmo assim, pode-se tentar explicar os comportamen-

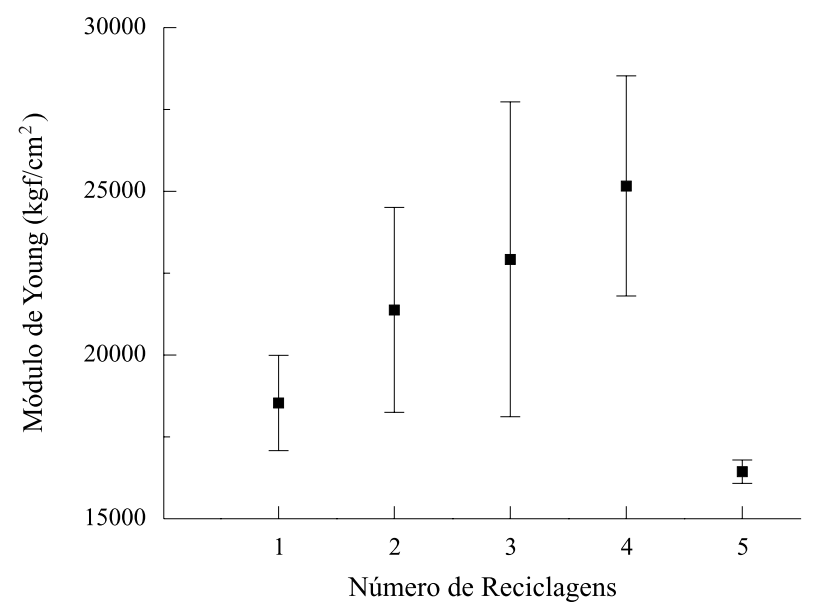

Figura 7. Medidas do módulo de Young de amostras provenientes de garrafas em função do número de reciclagens 


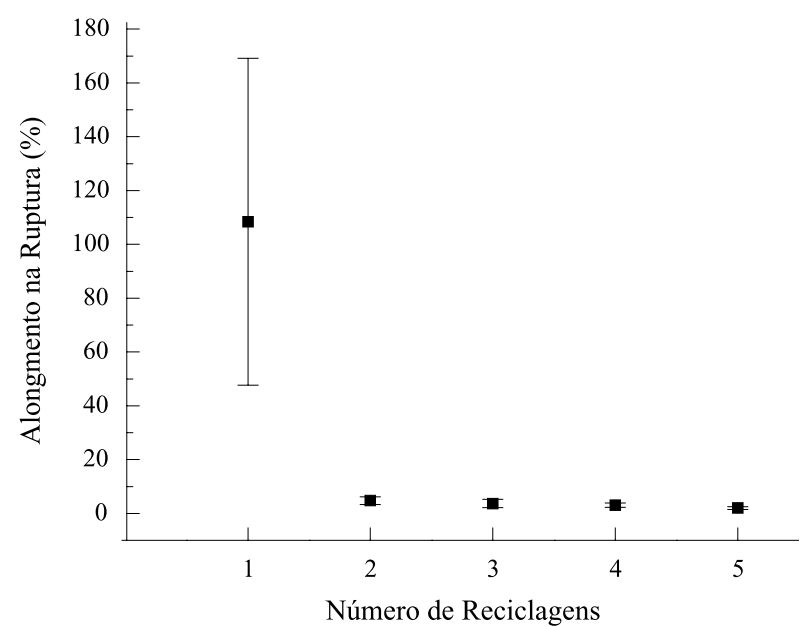

Figura 8. Medidas de alongamento na ruptura em tração em amostras provenientes de garrafas em função do número de reciclagens

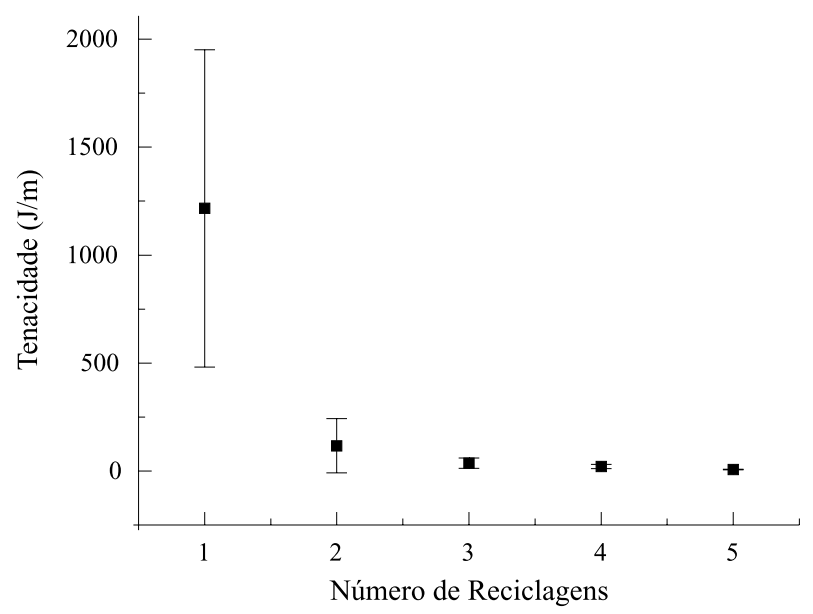

Figura 9. Medidas de tenacidade a partir de curvas de tração de amostras provenientes de garrafas em função do número de reciclagens

tos observados nas Figuras 7, 8 e 9 igualmente como os resultados de resistência ao impacto, ou seja, conforme se processam as reciclagens, ocorre diminuição do peso molecular além de um aumento da cristalinidade.

Com relação ao módulo de Young (Figura 7), o aumento da fase cristalina (de maior rigidez que a fase amorfa) fêz com que, na média, seu valor subisse conforme se processam as reciclagens. Em termos de alongamento na ruptura (Figura 8) a queda é explicada pela diminuição do peso molecular e pelo aumento da cristalinidade (aumenta a fase de maior oposição ao escoamento) conforme se aumenta o número de reciclagens. O comportamento da tenacidade (Figura 9) é muito semelhante ao observado com relação ao alongamento na ruptura. Isto já era de se esperar na medida em que a tenacidade é uma propriedade que envolve a força (resistência) e a dutilidade

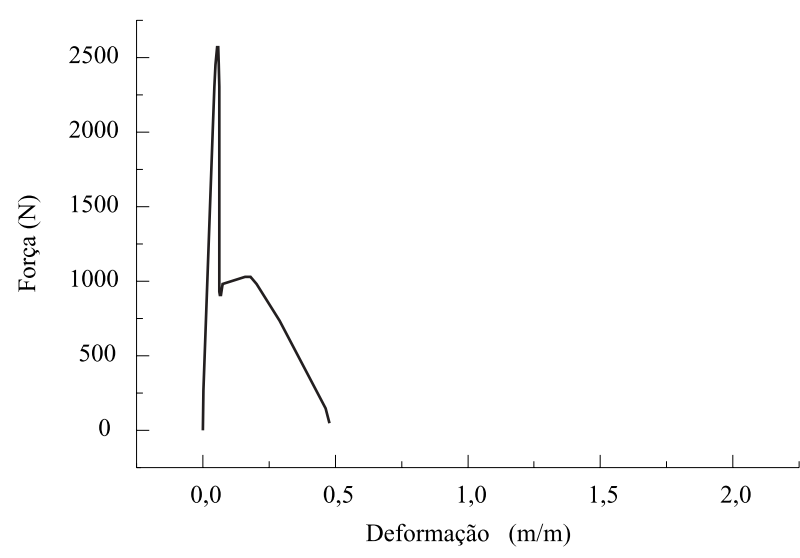

Figura 10. Gráfico força $X$ deformação em tração da amostra $G_{1-4}$

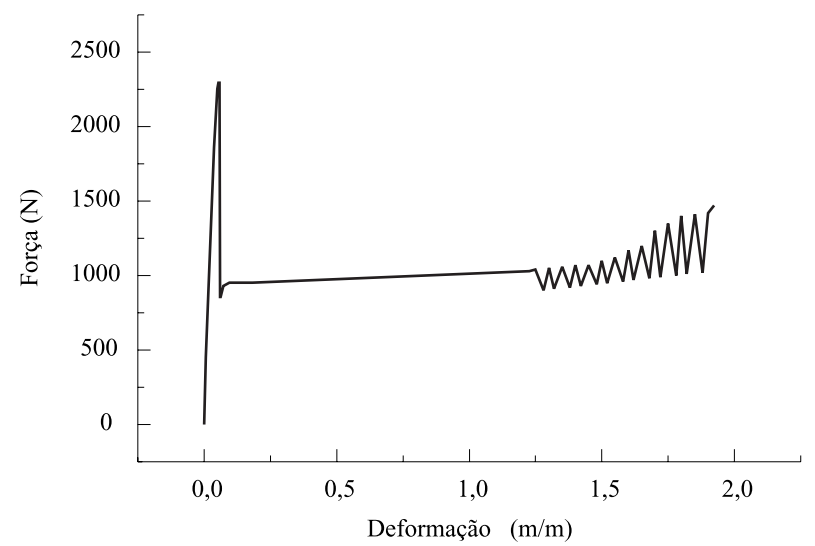

Figura 11. Gráfico força $X$ deformação em Tração da $A m o s t r a ~ G_{1-1}$

do polímero, tendo os comportamentos apresentados as mesmas razões de ocorrência do que os de propriedades correlatas.

É interessante comparar os valores de tenacidade e resistência ao impacto, que apesar de terem sido obtidos em testes diferentes (em termos de equipamento, metodologia e tratamento de amostras), têm a mesma unidade. Os valores de resistência ao impacto são sempre menores (variando de $17,28 \mathrm{~J} / \mathrm{m}$ a $5,73 \mathrm{~J} / \mathrm{m}$ ) do que os de tenacidade (variando de 1216,54 J/m a 6,72 $\mathrm{J} / \mathrm{m}$ ), em função do número de reciclagens, porém o comportamento é o mesmo (queda dos valores com o aumento do número de reciclagens).

Tanto para alongamento na ruptura quanto para a tenacidade, chama a atenção os resultados do primeiro passo, cujo desvio-padrão é muito maior que o apresentado nos passos subsequentes. Isto pode ser explicado pelos diferentes valores de elongação na ruptura, que foram causados por comportamentos de deformações plásticas variáveis dentro de um mesmo lote de amostras. As figuras 10 e 11 (gráficos força X deformação) ilustram tais diferenças, com amostras advindas de garrafas $\left(G_{1}\right)$ com valores de tenacidade 
de $391,8 \mathrm{~J} / \mathrm{m}$ e $2.102,3 \mathrm{~J} / \mathrm{m}$, respectivamente.

Sobre o comportamento exibido na Figura 11, especialmente na região de deformação 1,23 a 1,92 (123\% a 192\%), o material teve seu aspecto mudado radicalmente durante o ensaio, como uma espécie de franjeamento ("crazes"). Tal comportamento provavelmente deve ser resultado do escoamento irregular de esferulitos, cujas taxas de formação e crescimento (causada pela cristalização no estiramento) nesta região não conseguiram acompanhar a velocidade de deformação imposta pelo equipamento, causando a descontinuidade apresentada.

\section{Conclusões}

A injeção de corpos de prova a partir de garrafas moídas mostrou-se altamente produtiva, com níveis aceitáveis até o quarto passo, o que pode ser um indicativo que, para produtos $100 \%$ reciclados, a extrusão de "pellets" que se faz intermediariamente, pode ser eliminada. A mistura de flocos de garrafa com grânulos do material virgem para se obter produtos com propriedades mais próximas do virgem não é muito indicada para ser feita diretamente em injetora, pela diferença de densidade dos dois tipos de PET.

Em relação a influência do número de reciclagens em propriedades do PET pós-consumo, observou-se que o número de terminais carboxílicos aumentou cerca de $300 \%$ da primeira até a quinta reciclagem, indicando mudanças estruturais das macromoléculas (quebra de cadeias). Esta degradação e o aumento da cristalinidade (de $11 \%$ para a garrafa moída para $25 \%$ na quinta reciclagem) explicaram o comportamento de propriedades mecânicas, ou seja, o aumento no módulo de Young e a perda de dutilidade. Porém, algumas amostras de garrafa reciclada $\left(\mathrm{G}_{1}\right)$ por exemplo, apresentaram dutilidade altíssima, o que sugere a continuidade do trabalho para estudar esta característica visando tornar este comportamento típico de produto reciclado a partir de garrafas de PET, o que certamente lhe daria utilização muito mais nobre do que é dado hoje em dia.

\section{Agradecimentos}

Os autores agradecem a Gustavo Frattini pela ajuda em vários momentos do trabalho. Ainda à FAPESP pelo financiamento do projeto (número 1995 / 3257 2), a CAPES e ao CNPq pela cessão das bolsas.

\section{Referências Bibliográficas}

1. Ehrig, Raymond J. - "Plastics recycling: products and processes", Hanser Publishers, Nova Iorque, 289 p. (1992)

2. Mancini, S. D.; Frattini, e Zanin, M. - "Reciclagem como alternativa viável para a minimização dos resíduos sólidos urbanos", 4ª Reunião da Sociedade Brasileira de Pesquisadores Nikkeis, São Carlos, SP (1996)

3. Mancini, S. D. - "Caracterização física dos materiais processados na Usina de Separação de Lixo e Compostagem de Resíduos Urbanos de Araraquara-SP com ênfase em materiais plásticos e estudo da influência de múltiplas reciclagens em propriedades do PET pósconumo", Dissertação de Mestrado, Universidade Federal, São Carlos, 191p. (1996)

4. "Polyethylene terephthalate bottles and polyehylene terephthalate g bottles”, In: United States Pharmacopoeia, p. 1784-1787 (1995)

5. Reich, L.; Stivala, S. S. - "Elements of Polymer Degradation", McGraw Hill, Nova Iorque, 361 p. (1971)

6. Day, M. \& Willes, D. M. - "Photochemical degradation of poly(ethylene terephthalate) II effect of wavelength and environment on the decomposition process", J. Appl. Polym. Sci., v.16, p. 191-202 (1972)

7. Fann, D. M.\& Huang, S. K. \& Lee, J. Y. - “Kinetics and thermal crystalinity of recycled PET. II. Topographic study on thermal crystalinity of the injection molded recycled PET', J. Appl. Polym. Sci., v. 61, 261-271 (1996)

8. Pearce, E. M.; Bulkin, B. J. \& Ng, M. Y. - "Fourier transform IR spectroscopy for the study of polymer degradation: thermal and thermooxidative degradation of polyethylene terephthalate", In: Polymer Characterization, Clara D. Craver (ed.) a partir do 181st Meeting of the American Chemical Society (29/03-03/ 04 - 1981), Atlanta, American Chemical Society, p. 571-594 (1983)

9. Klemchuck, P. P. - "Polymer Stabilization and Degradation", ACS Symposium Series, American Chemical Society, Washington, 446 p. (1985) 
10. Ranby, B. \& Rabek, J. F. - "Photodegradation, photo-oxidation and photostabilization of polymers: principles and applications", John Wiley \& Sons (ed.), Londres, 573 p. (1975)

11. La Mantia, F. P. \& VINCI, M. - "Recycling poly (ethylene terephtalate)”, Polymer Degradation and Stability, Reino Unido, n 45, 121-125 (1994).

12. The Merck Index, $8^{\text {a }}$ ed., Merck \& Co Inc., Nova Jérsei, 1713 p. (1968)

13. American Society of Testing Materials - "Standard test method for tensile properties of plastics / D 638-90”, Filadélfia, 08 (01), p. 157-168 (1991)

14. Pohl, Herbert A. - "Determination of carboxyl end groups in a polyester, polyethylene terephthalate", Analytical Chemistry, v.26, n.10, p.1614-1616 (1954)

15. Oriani, L. A. G. - "Estudo da estabilidade estrutural de fibras de nylon 6 e sua relação com o processo de nivelamento de cor", Dissertação de Mestrado, Universidade Federal, São Carlos, p. 74 (1989)

16. Brolly, I. B.; Bower, D. I. \& Ward, I. M. "Diffusion and sorption of $\mathrm{CO}_{2}$ in poly (ethylene terephthalate) and poly (ethylene naphtalate)", J. of Polym. Sci. Part B: Polymer Physics, EUA, v. 34 , p. $769-780$ (1996)

17. American Society of Testing Materials "Standard test method for flow rates of thermoplastics by extrusion plastometer / D 1238-90b", Fildadélfia, 08 (02), p.214-217 (1991)

18. American Society of Testing Materials "Standard test methods for impact resistance of plastics and electrical insulating materials / D 256-90b", Filadélfia. 08 (01), p.58-74 (1991)

Recebido: 23/09/97 Aprovado: 24/03/98 